\title{
A low-cost development of automatic weather station based on Arduino for monitoring precipitable water vapor
}

\author{
Wayan Suparta', Aris Warsita ${ }^{2}, \operatorname{Ircham}^{3}$ \\ ${ }^{1}$ Department of Electrical Engineering, Institut Teknologi Nasional Yogyakarta, Yogyakarta, Indonesia \\ ${ }^{2}$ Department of Mechanical Vocational Engineering, Institut Teknologi Nasional Yogyakarta, Yogyakarta, Indonesia \\ ${ }^{3}$ Department of Civil Engineering, Institut Teknologi Nasional Yogyakarta, Yogyakarta, Indonesia
}

\section{Article Info}

Article history:

Received May 23, 2021

Revised Jul 27, 2021

Accepted Aug 31, 2021

\section{Keywords:}

Arduino Uno

BME280

Micro scale

Monitoring

Precipitable water vapor

\begin{abstract}
Water vapor is the engine of the weather system. Continuous monitoring of its variability on spatial and temporal scales is essential to help improve weather forecasts. This research aims to develop an automatic weather station at low cost using an Arduino microcontroller to monitor precipitable water vapor (PWV) on a micro-scale. The surface meteorological data measured from the BME280 sensor is used to determine the PWV. Our lowcost systems also consisted of a DS3231 real-time clock (RTC) module, a $16 \times 2$ liquid crystal display (LCD) module with an $\mathrm{I}^{2} \mathrm{C}$, and a micro-secure digital (micro-SD) card. The core of the system employed the Arduino Uno surface mount device (SMD) R3 board. The measurement results for longterm monitoring at the tested sites (ITNY and GUWO) found that the daily mean error of temperature and humidity values were $1.30 \%$ and $3.16 \%$, respectively. While the error of air pressure and PWV were $0.092 \%$ and $2.61 \%$, respectively. The PWV value is higher when the sun is very active or during a thunderstorm. The developed weather system is also capable of measuring altitude on pressure measurements and automatically stores daily data. With a total cost below 50 dollars, all major and support systems developed are fully functional and stable for long-term measurements.
\end{abstract}

This is an open access article under the CC BY-SA license.

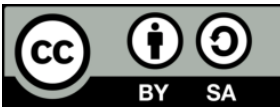

\section{Corresponding Author:}

Wayan Suparta

Department of Electrical Engineering

Institut Teknologi Nasional Yogyakarta

Street Babarsari, Tambakbayan, Caturtunggal, Depok, Sleman, Yogyakarta, Indonesia

Email: wayan@itny.ac.id, drwaynesparta@gmail.com

\section{INTRODUCTION}

Long-term meteorological data is a necessity not only for weather forecasting and climate modeling but also for the mitigation of disasters in addition to climate change adaption [1]-[3]. If used by ocean travelers or working in the form of surveys in the wilderness, and exploration in oceans or mountains in remote areas where all sources of electricity and lines of communication are limited, basic meteorological data are required for weather forecasting. On the other hand, ground-based meteorological data is also required to verify meteorological measurements made by space-based such as satellites [4]. However, the weather forecast data currently available on both ground-based meteorological stations or meteorological data from satellites has a very broad coverage. Because every location point on earth has certain weather conditions, it is very expensive to build meteorological stations for instance every $10 \mathrm{~km}$ or $25 \mathrm{~km}$ radius. The cheapest method of dealing with weather differences between adjacent stations is by forecasting the weather through interpolation [5]-[7].

Different topography and climate in a region will have different intensities and impacts when compared to other regions. For example, one of the interesting weather phenomena in tropical climates is the 
local rain that we often experience, as well as local storms. Rain will form when the amount of water vapor in the atmosphere condenses and forms rain droplets. This atmospheric water vapor before forming raindrops is known as precipitable water vapor (PWV). Water vapor plays a major role in the dynamics of atmospheric circulation which modifies the flow of radiant energy, attenuating the electromagnetic spectrum, and its distribution correlated with clouds and storms [8], [9]. PWV becomes important in the collection of meteorological data. So far, there is no sensor to directly measure the PWV. The variations of PWV are sometimes associated with rain or humidity patterns. Associated with this parameter, weather stations usually have rainfall parameters, in addition to temperature, air pressure, and relative humidity. Now, the modern weather station (automatic weather station (AWS)) has been equipped with an upgraded data logger that also contains wind parameters (speed and direction), solar radiation, volcanic activity, flood activity (e.g., tsunamis, landslides), weather forecasts, and space weather. Based on the meteorological data, Suparta and Alhasa [10] determined the PWV using the least-squares method or multiple linear regressions (MLR) with the input of temperature, pressure, and relative humidity. Suparta [11] has also developed a Raspi-Met system for monitoring and managing meteorological parameters in remote areas using the Raspberry Pi3 and a Vaisala PTU300 sensor, and these systems have long term reliability performance but are still relatively expensive.

This research aims to develop a low-cost weather system using a microcontroller to measure PWV and other meteorological parameters, especially for remote locations on a micro-scale. The existence of this system is expected to support or to complement the lack of weather data, especially in remote areas with limited access to electricity and access to weather information via the internet or communication systems. One of the microcontrollers used is the automatic voltage regulator (AVR) family, namely the Arduino Uno. Arduino is an open-source electronics platform based on easy-to-use hardware and software at a very affordable price and can be learned even with minimal knowledge of hardware and software [12]-[14]. The following are some researchers who have used the Arduino as an AWS mini, e.g. [15] designed a low-cost weather station using Arduino Uno with a TMP36 temperature sensor, RHT03 relative humidity sensor, and BMP085 barometric sensor for detecting environmental changes. While [16] proposed an internet of things (IoT-based) smart weather system with five different meteorological sensors connected to the Arduino Uno to measure humidity, object finding, temperature, raindrops, and Carbon dioxide $\left(\mathrm{CO}_{2}\right)$. Furthermore, the development of a weather station using Arduino Mega 2560 with DHT-22 sensor, BMP085 barometric pressure sensor, SSHU005 water detection sensor, zirconate titanate (PZT) LDT0-028 hail detection, 6710-WINd02 anemometer, and MQ135 air quality sensor was conducted by [17] to collect and store ambient temperature, relative humidity, barometric pressure, wind speed, and air quality data for renewable energy systems in Madrid, Spain. BME280 with ESP8266EX was also used for awareness and early warning in conditions of severe weather in Bucharest, Romania [18]. Meanwhile our research carried out is very simple and never been reported before, using only the Arduino Uno and the BME280 sensor to monitor PWV. Four other meteorological parameters are also generated from the system, namely surface temperature, pressure, relative humidity, and altitude. Subsequently, the data were characterized on a daily to weekly basis along with statistical analysis for validation purposes. Two natural phenomena are also discussed to ensure that the developed system is stable, sensitive, and reliable. These results will be the initial idea for developing more complex systems in the future.

\section{RESEARCH METHOD}

\subsection{System design and implementation}

As a basis for designing and implementing the system being built, the module used in this work consists of an Arduino Uno R3 surface mount device (SMD) version of the ATmega328P microcontroller where Arduino is an open-source physical computing development ecosystem for multipurpose [12], [19]. The second module is a BME280 sensor, the next generation of sensors from Bosch ${ }^{\mathrm{TM}}$ produced by Adafruit [20]. In this project, a GY-BME280-5V series with a BMP280 chip is employed. The third module is a DS3231 real-time clock (RTC), a chip that has the capability and high accuracy to run the time and date on electronic circuits. In this study, the maxim integrated DS3231 RTC chip was used. The fourth module is an inter-integrated circuit $\left(\mathrm{I}^{2} \mathrm{C}\right)$, a communication protocol developed by Philips Semiconductor. It is normally connected to a liquid crystal display (LCD) where this project, a 16×2 blue LCD with a default address of 0x27 for PCF8574T is used to display the output of measurements. The last module is a micro-SD card that uses the standard serial peripheral interface (SPI) interface for communications such as MISO, MOSI, SCK, and CS signals.

After carried out the system requirements analysis with considering efficiency and low cost, the next step is its implementation. The connection of each component and their power requirements are carefully considered. In this system, one device or module is connected to the Arduino via SPI, and others are communicated via $\mathrm{I}^{2} \mathrm{C}$ as shown in Table 1. Overall, the designed system has main parts with connections as 
shown in the block diagram of Figure 1. The overall cost of the system in Figure 1 is about $\$ 30.00$ from the online shop or $\$ 45.00$ with shipping cost if purchased separately. This price is 100 times cheaper if compared to the industrial scale of Vaisala PTU300 sensors or broadband meteorological sensors (MET3A/MET4A) from Paroscientific, Inc.

Table 1. The pin connection on Arduino Uno for peripherals used

\begin{tabular}{ccl}
\hline Arduino Pin & Connection/Function & \multicolumn{1}{c}{ Remarks } \\
\hline A4 & SDA & SDA analog pin on BME280, DS3231 RTC, and I IC LCD \\
A5 & SCL & SCL analog pin on BME280, DS3231 RTC, and I IC LCD \\
10 & CS & SS (Slave Select) digital pin (CS = Chip Select) on SD card \\
11 & MOSI & DI digital pin (MOSI = Master Out Slave in) on SD card \\
12 & MISO & DO digital pin (MISO = Master in Slave Out) on SD card \\
13 & SCK & CLK digital pin (SCK = System Clock) on SD card \\
GND & GND & Ground pin for powering all support modules \\
Vcc & $+5 V$ & Vcc pin for powering the SD card, DS3231 RTC, and I IC LCD \\
Vcc & $+3.3 \mathrm{~V}$ & Vcc pin (50 mA) for powering the BME280 \\
\hline
\end{tabular}

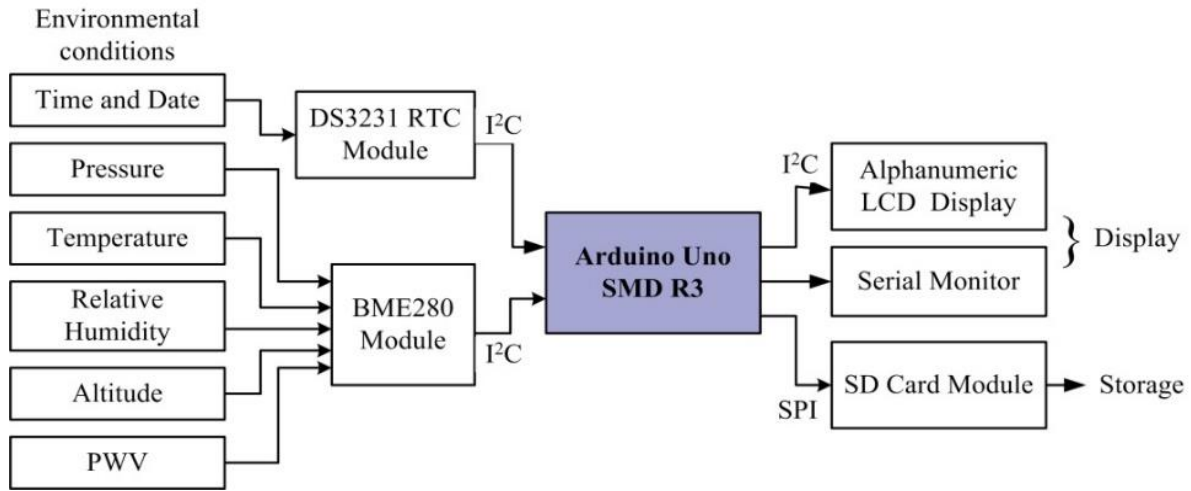

Figure 1. Block diagram of a low-cost weather station development

\subsection{Design implementation}

The main hearth of this weather system is the Arduino Uno SMD R3 with the ATmega328P microcontroller inside [21]. The BME280 sensor and DS3231 RTC are connected to Arduino as input while the ones that act as outputs are an $\mathrm{I}^{2} \mathrm{C}$ LCD and SD card. The pin connections on the Arduino Uno for the external devices used in this study are described in Table 1. Note that the connection pins for SCL and SDA are possibly different if we use different types of Arduino boards.

The sensor and RTC devices are connected via the $\mathrm{I}^{2} \mathrm{C}$ protocol and act as slaves with the device address set as in Table 2. Since the I/O devices connected to the Arduino are low-cost, all the power required by the system is simple and supplied directly from the laptop connected via USB port. The ground section is connected to the GND pin on the Arduino and other devices. An individual library of devices is also provided by Arduino for easy programming.

Table 2. The device address for $\mathrm{I}^{2} \mathrm{C}$ protocol and their library

\begin{tabular}{ccc}
\hline Devices & Device Address & Library \\
\hline BME280 & 0x76 & Adafruit_BME280.h \\
DS3231 RTC & 0x68 & RTClib.h \\
I $^{2}$ C LCD & 0x27 & LiquidCrystal_I'C.h \\
SD card & SPI (CS, MOSI, MISO, SCK) & SD.h \\
\hline
\end{tabular}

\subsection{Programming design for the system}

The core business of the Arduino platform is that all coding is available for free and discussed in a dedicated Arduino forum. They write the program using the Arduino programming language with a dialect similar to $\mathrm{C}$ through the Arduino IDE version 1.8.13 [14]. Furthermore, the programming algorithm for weather monitoring in this project is presented in Figure 2. In general, the program is composed of several sub-programs, namely the initialization of the equipment used for the first time. It contains instructions to run only once at the initial step and the loop will be executed according to desired conditions. The program must be able to run all input and output components and successfully display them on an LCD or serial monitor. 
For long-term data analysis, measurement results are stored on an SD card with a predetermined data format, namely txt. The availability of long-term data will be useful for future analysis purposes. Therefore, automatic daily data storage to the micro-SD card with data in text format is created with the filename: yyyymmdd.txt (where $\mathrm{y}, \mathrm{m}$, and d represent year, month, and day, respectively). The advantage of storing data on a daily basis is easy to track data errors and reduces file sizes.

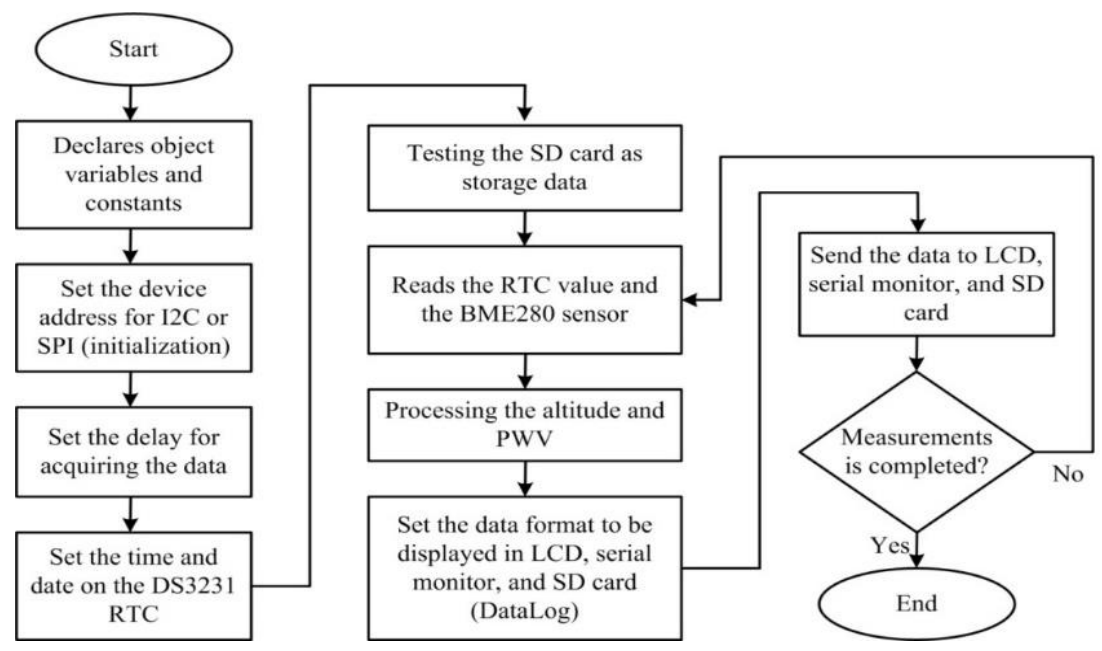

Figure 2. Programming algorithm flowchart for weather monitoring

To find out that the BME280 sensor has worked properly in accordance with environmental conditions, it can be activated via the following main program.

Pressure $=$ bme280.readPressure ()$/ 100.0 \mathrm{~F} ; / /$ get pressure in $\mathrm{mb}(1 \mathrm{mb}=1 \mathrm{hPa})$

Pair = bme280.seaLevelForAltitude(ALTITUDE, Pressure); //get pressure in mb based on altitude

Tair = bme280.readTemperature(); // get temperature in ${ }^{\circ} \mathrm{C}$

$\mathrm{RH}=$ bme280.readHumidity(); // get humidity in $\mathrm{RH} \%$

ALT = bme280.readAltitude(SLP_HPA); // get altitude in meters

$P W V=103.6103+(-0.1707 *$ Pair $)+2.3614 *$ Tair $+0.623 * R H ; / / g e t P W V$ in $\mathrm{mm}$

Note that the ALTITUDE value for the ITNY and GUWO sites is set to zero, at which point the sensor can find its altitude automatically. The SLP_HPA is set to standard atmospheric pressure at mean sea level (1013.25 mbar). Furthermore, the PWV value cannot be directly measured from BME280 sensors. It was determined by the least-squares or MLR method as proposed by [10] with the following (1).

$$
P W V=\beta_{0}+\beta_{1} P_{\text {air }}+\beta_{2} T_{\text {air }}+\beta_{3} R H
$$

where the regression coefficient values, $\beta_{0}=103.6103, \beta_{1}=-0.1707, \beta_{2}=2.3614$, and $\beta_{3}=0.623$ are for intercept, pressure $\left(P_{\text {air }}\right)$, temperature $\left(T_{\text {air }}\right)$, and relative humidity $(\mathrm{RH})$, respectively. These values were obtained from averaged three stations: UKMB (Bangi, Malaysia), NTUS (Singapore), and UMSK (Kota Kinabalu, Sabah, Malaysia) for the year of 2012 which roughly representative for the Southeast Asia region.

\subsection{Testing the system}

The tests carried out for this study are divided into two main parts, namely measurement testing and data storage testing. Measurement tests include the BME280 sensor readings (temperature, relative humidity, air pressure, altitude, and PWV). The results of these readings are displayed on the LCD and serial monitor. Data storage testing is also the main concern so that long-term data can be stored and analyzed. It is marked by successfully created a file and store data automatically to the SD card.

To find out that the reading made by the BME280 sensor is accurate and corresponds to the actual environmental conditions, experiments were carried out in two sites, namely the ITNY Campus (ITNY: $7^{\circ}$ 46' $24.72^{\prime} \mathrm{S}, 110^{\circ} 24^{\prime} 58.39^{\prime \prime} \mathrm{E}$, and an altitude of $145 \mathrm{~m}$ ) and the Maguwoharjo house (GUWO: $7^{\circ} 44^{\prime} 54.35^{\prime \prime}$ $\mathrm{S}, 110^{\circ} 26^{\prime} 15.95^{\prime \prime} \mathrm{E}$, and an altitude of $\left.171 \mathrm{~m}\right)$. Figure 3 shows the site of the experiment. Both sites are located in the Sleman Regency of the Special Region of Yogyakarta (Java Island), Indonesia. As can be seen 
from the map on the left side, the two sites appear to be overlapping even though the geographical distance between the two sites is about $8 \mathrm{~km}$. To distinguish the two sites overlapped on the left side, the map on the right (adapted from Google Maps) clarifies the position of the two sites. In addition, testing is also carried out for long-term data or at least 24 hours indoors and outdoors to determine the stability of the sensor and the actual daily characteristics of the weather.

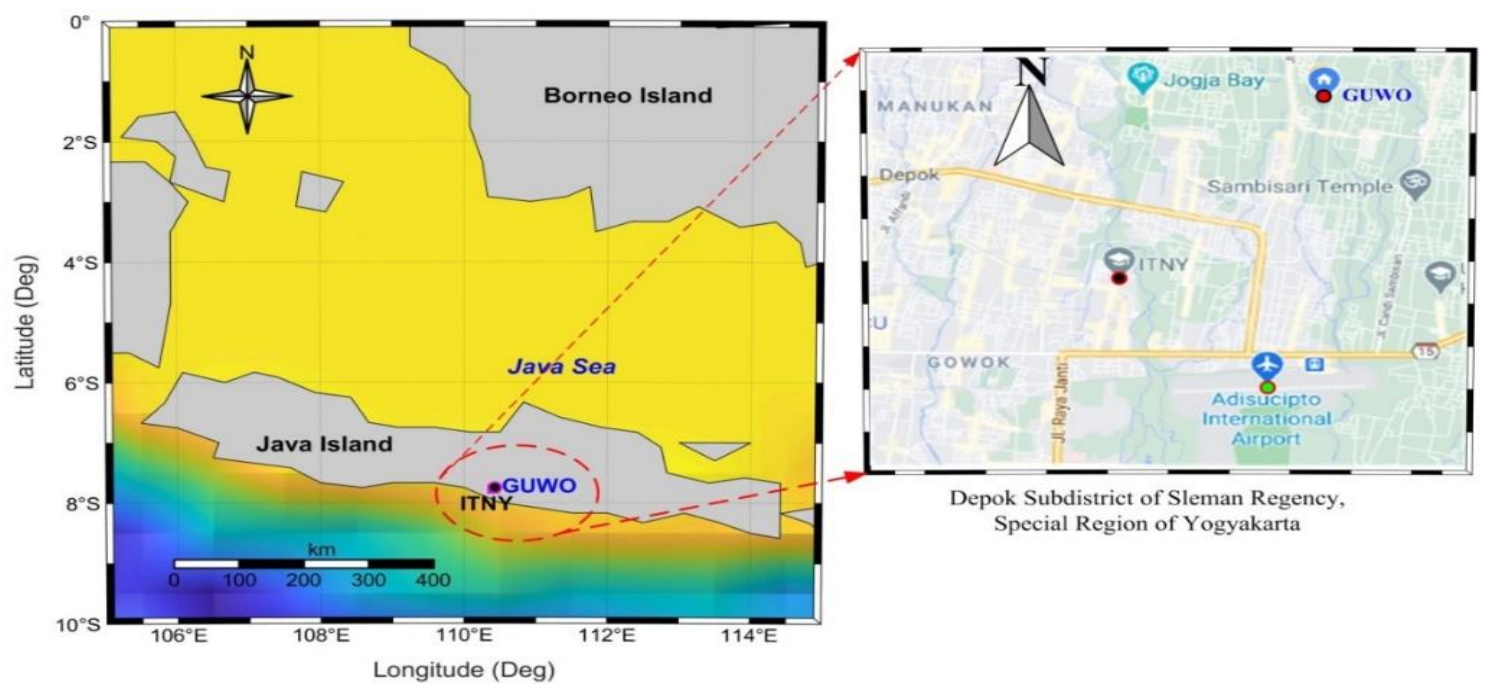

Figure 3. The location of experiment for data collection (ITNY and GUWO sites)

To validate the accuracy of the measurement results, for example, the reading of air pressure $\left(P_{\text {air }}\right)$ can be compared with the Hypsometric formula as proposed by WMO [22].

$$
P_{\text {air }}=P_{0}\left(1-\frac{\beta \text { Alti }}{T_{\text {air }}+\beta \text { Alti }+273.15}\right)^{\alpha}
$$

where $P_{0}$ is the standard atmospheric pressure at mean sea level $(1013.25 \mathrm{mb}), \beta$ is standard temperature lapse rate $[0.0065 \mathrm{~K} / \mathrm{m}], T_{\text {air }}$ is the temperature reading from a sensor $\left({ }^{\circ} \mathrm{C}\right)$, and $\alpha$ is a constant $\left(\alpha=\frac{g M}{R \beta}=\right.$ $\frac{(9.80665)(28.9644)}{(8314.32)(0.0065)}=5.257$ and Alti is an altitude of a site measured from the mean sea level to the height at which the meteorological sensors take measurements. The altitude (Alti) of the site can be determined as shown in [23].

$$
\text { Alti }=h_{0}+\frac{T_{0}}{\beta}\left[\left(\frac{P_{\text {air }}}{P_{0}}\right)^{-1 / \alpha}-1\right]=\frac{\left[\left(\frac{P_{o}}{P_{\text {air }}}\right)^{-\frac{g M}{R L_{o}}}-1\right]\left(T_{\text {air }}+273.15\right)}{\beta}
$$

where $h_{0}$ is the altitude of the site $(\mathrm{m})$ and $\mathrm{M}$ is the mean molar mass for dry air $(28.9645 \mathrm{~kg} / \mathrm{kmol})$. At the troposphere level (mean sea level), $h_{0}=0, T_{0}$ is a standard temperature $\left(288.15 \mathrm{~K}\right.$, or $15^{\circ} \mathrm{C}$ ), and the air pressure $\left(P_{\text {air }}\right)$ will be $1013.25 \mathrm{mb}$. With the limitations of certain models for estimating surface temperature $\left(T_{\text {air }}\right)$ and relative humidity $(R H)$ with available inputs, these two parameters will also be compared with measurements at the reference station. To validate our system, the percentage error between the measurement and the estimation is formulated as.

$$
\text { Error }(\%)=\frac{\text { Average of measurement }- \text { Average of estimation }}{\text { Average of estimation }} \times 100 \%
$$

\section{RESULTS AND DISCUSSION}

\subsection{Testing results}

Figure 4 shows an example of the indoor experiment results for the ITNY site. The measurement result on the LCD for data recorded every one second is displayed in Figure 4(a). Since the LCD used is only one $16 \times 2$ LCD to display all parameters, the first LCD flash will display the time, date, temperature, and day 
of the week. The second flash will display the air pressure, altitude, relative humidity, and PWV. Meanwhile, the data displayed on the serial monitor via COM3 (USB) as in Figure 4(b) where all parameters and measurement times can be displayed completely.

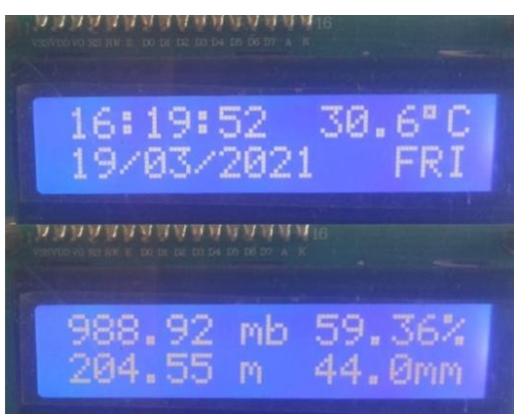

(a)

\begin{tabular}{|c|c|c|c|c|c|c|c|c|}
\hline \multicolumn{6}{|l|}{ (1) сом3 } & \multirow[t]{2}{*}{-} & $\square$ & $x$ \\
\hline & & & & & & & \multicolumn{2}{|r|}{ Send } \\
\hline \multicolumn{7}{|c|}{$\begin{array}{l}\text { MOBILE WEATHER STATION WITH ARDUINO a BME280 SEIHSOR } \\
\text { Initializing BME } 280 \text { sensor....K. } \\
\text { Initializing SD card... successful. }\end{array}$} & & A \\
\hline DATE & TIME & $\mathrm{I}\left({ }^{\circ} \mathrm{C}\right)$ & H (3) & $P(m b)$ & ALT (m) & PWV (mm) & & \\
\hline $31-03-2021$ & $11: 02: 07$ & 29.53 & 66.33 & 989.57 & 199.01 & 45.74 & & \\
\hline $31-03-2021$ & $11: 02: 08$ & 29.53 & 66.35 & 989.57 & 199.05 & 45.76 & & \\
\hline $31-03-2021$ & $11: 02: 09$ & 29.53 & 66.34 & 989.55 & 199.20 & 45.75 & & \\
\hline $31-03-2021$ & $11: 02: 10$ & 29.53 & 66.40 & 989.56 & 199.12 & 45.79 & & \\
\hline $31-03-2021$ & $11: 02: 11$ & 29.53 & 66.41 & 989.56 & 199.17 & 45.80 & & \\
\hline $31-03-2021$ & $11: 02: 12$ & 29.53 & 66.44 & 989.57 & 199.07 & 45.81 & & \\
\hline $31-03-2021$ & $11: 02: 13$ & 29.53 & 66.53 & 989.55 & 199.20 & 45.88 & & \\
\hline $31-03-2021$ & $11: 02: 14$ & 29.53 & 66.52 & 989.57 & 199.05 & 45.87 & & \\
\hline $31-03-2021$ & $11: 02: 15$ & 29.54 & 66.59 & 989.58 & 198.98 & 45.93 & & \\
\hline $31-03-2021$ & $11: 02: 16$ & 29.53 & 66.52 & 989.56 & 199.13 & 45.87 & & \\
\hline 31-03-2021 & $11: 02: 17$ & 29.53 & 66.50 & 989.59 & 198.92 & 45.85 & & v \\
\hline \multicolumn{4}{|c|}{$\square$ Autoscroll $\square$ Show timestamp } & Newine & $v$ & 00 baud & & ar output \\
\hline
\end{tabular}

(b)

Figure 4. The measurement results displayed on the; (a) LCD, (b) serial monitor

As can be seen from Figure 4, the data will be displayed on the LCD and serial communication when the BME280 sensor initialization is successful. The data will be recorded into the SD card if the SD card initialization is also successful. A file that has been successfully created in *.txt format for the first time will be displayed on the serial monitor, and when the same program is run for the second time or repeated, the next data will be saved and appended to today's file name. The file name is generated automatically by the system based on the current date and the contents of the file will be the same as that displayed on the serial monitor (see Figure 4 (b)). The problem will appear when one column of data is added if another sensor is connected.

\subsection{Characteristics of PWV and other meteorological parameters}

To ensure the system developed is truthful and capable of measuring based on real environmental conditions, an amount of data has been collected ranged from a few hours to several days. However, only completed daily data ( 24 hours) from indoor and outdoor measurements at both sites are selected and presented as in Figure 5. Because there is only one system, measurements at both sites for indoors and outdoors are carried out interchangeably at different times. The main point is to test the system stability, long-term measurements stability, and the quality of the data collected.

As shown in Figure 5, the data collected in this region is based on local time (LT = GMT +7$)$. In Figure 5(a), the variation in surface temperature increases when the sun is active and reaches a peak at midday. For relative humidity, the pattern is obtained opposite the surface temperature. For pressure readings, it depends on sea level and tidal conditions where a bimodal pattern was found in this tropical region. This pressure pattern is also opposite to the altitude pattern, meaning that the higher the pressure (decreasing pressure value), the altitude is increased or vice versa. The lower the station altitude, the pressure value will come up to the standard atmospheric pressure $(1013.25 \mathrm{mb})$. In this case, the altitude of the ITNY is lower than the GUWO although the ITNY site for this system is located in the 5th-floor building. The altitude readings are also validated with the GPS altimeter from the mobile apps, for example, when GUWO at $9.00 \mathrm{am}$, the GPS altimeter reading is $171 \mathrm{~m}$ which is about $4 \%$ lower as compared to the sensor reading. In the last panel, it can be seen that PWV is predominantly influenced by surface temperature.

One interesting feature presented during outdoor measurement on March 14, 2021, an extreme peak of temperature followed by relative humidity and PWV has occurred, where the surface temperature and PWV reached more than $40^{\circ} \mathrm{C}$ and $55 \mathrm{~mm}$, respectively. The high peak with ripples was coincidentally triggered by strong winds and rain. The same pattern has also occurred at the ITNY site (see Figure 5(b)). It looks that the PWV pattern after 15:00 does not follow a temperature pattern but rather a humidity. This condition is remarkable as an anomaly due to rain. Thus, atmospheric water vapor is sometimes associated with the frequency of rainfall and an increased risk of flooding due to global climate change [24].

To verify the pattern formed from the measurement results and at the same time validate the measurement results, a new similar weather system was added so that each site can take measurements at the same time. During this experiment, one week of data for outdoor measurements at the GUWO site and ITNY 
site is presented as in Figure 6(a) and Figure 6(b), respectively. The date displayed in the panel shows the midday when the measurement data starts at 00:00 until it ends at 23:59:59 local time. Now, it is clear that the variation in meteorological parameters from day to day is almost the same as long as there is no extreme weather. The PWV pattern is confirmed to follow the relative humidity pattern. However, at the temperature above $37^{\circ} \mathrm{C}$ and relative humidity as shown in $40 \%$, the PWV pattern tends to follow variations in temperature patterns. This indicates that a PWV above $50 \mathrm{~mm}$ will result in extreme weather such as thunderstorms. For example, as shown by the red dots arrow on April 4, 2021, there have been strong winds due to the effects of Typhoon Seroja from Eastern Indonesia, which affected the Sleman and Yogyakarta City regions with several fallen trees and power failures [25]. As a result, the electricity went out for more than 3 hours (no data during this time). In addition, an earthquake measuring 6.1 magnitudes rocked Malang, East Java, on April 10, 2021, at 14.05 Western Indonesian Time. The epicenter was in the sea at a depth of $80 \mathrm{~km}$, $96 \mathrm{~km}$ south of Kepanjen City, Malang. Apart from the south of East Java, the earthquake was also felt in Solo, Yogyakarta, Wonogiri, and surrounding areas [26]. The vibrations of this earthquake increased the surface temperature to more than $40^{\circ} \mathrm{C}$.

Detail of daily average comparison for one-week data at both sites is presented in Table 3 . The negative value in Table 3 shows that the measurement data is lower than the estimation or reference value. This difference may occur because the station position and weather conditions are different from those in other places. Since the surface temperature and relative humidity are not estimated with any models, these two parameters are compared with nearby meteorological data which is Yogyakarta Adisucipto International Airport (only $\sim 2 \mathrm{~km}$ from ITNY campus or see Figure 3 on the right side). However, the measured historical data at this station is not available online. Therefore, the daily measurement data from April 4 to 10, 2021 from the BMKG Sleman climatology station (namely Mlati) with a WMO ID: 96851 ( $7^{\circ} 43^{\prime}$ 51.6" S, $110^{\circ}$ $21^{\prime} 14.4$ " E, and an elevation of $182 \mathrm{~m}$ ) is employed [27]. The geographical distance between MLATIGUWO and MLATI-ITNY is approximately 9 and $8 \mathrm{~km}$, respectively.

Figure 7 shows the validation of the surface temperature and relative humidity on a daily basis for a week. The correlation between measurement and the reference values is depicted in each figure. Note that the MLATI station provides minimum, average, and maximum values for daily temperature data while relative humidity is provided only on a daily average. No pressure data provided online in this reference station. The two measurements from the developed system show moderate to strong correlation with the reference value, significantly at the $99 \%$ confidence level, except that the maximum temperature on April 10, 2021, which was possibly impacted by the Malang earthquake vibrations. This appears to be similar to the initial report of [28] where the Emilia earthquake can cause surface temperature anomalies, and this will be an interesting further study. Overall, from daily observations, the difference in the results of measurements indoors and outdoors shows the quality or sensitivity of a sensor which also depends on local weather conditions.

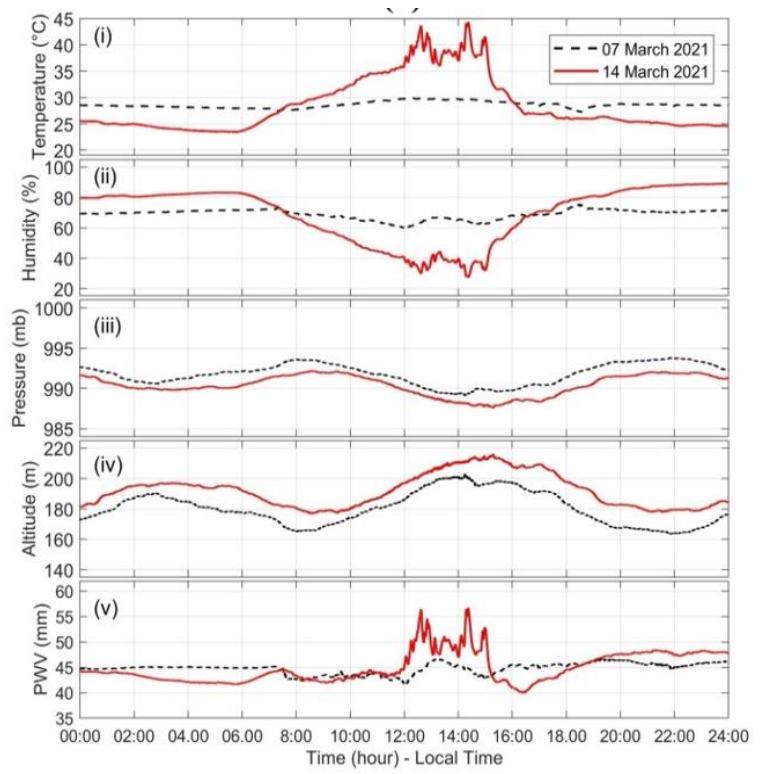

(a)

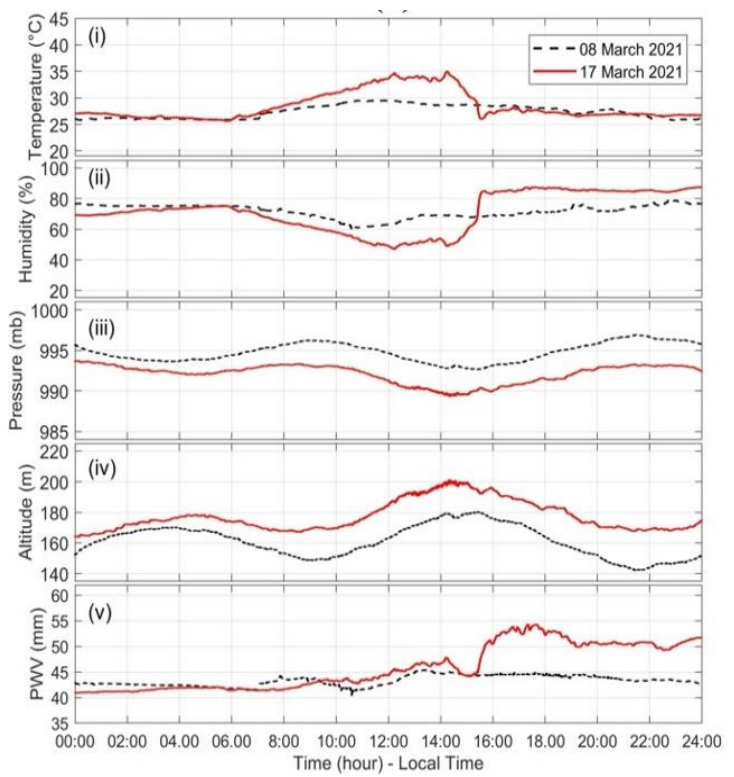

(b)

Figure 5. Monitoring of PWV and other meteorological parameters for one second measurement intervals at; (a) GUWO, (b) ITNY sites 


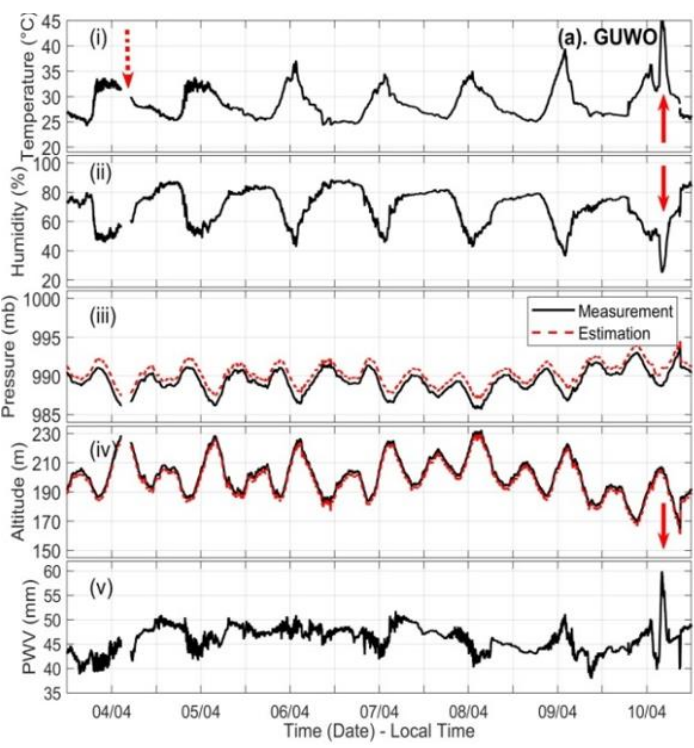

(a)

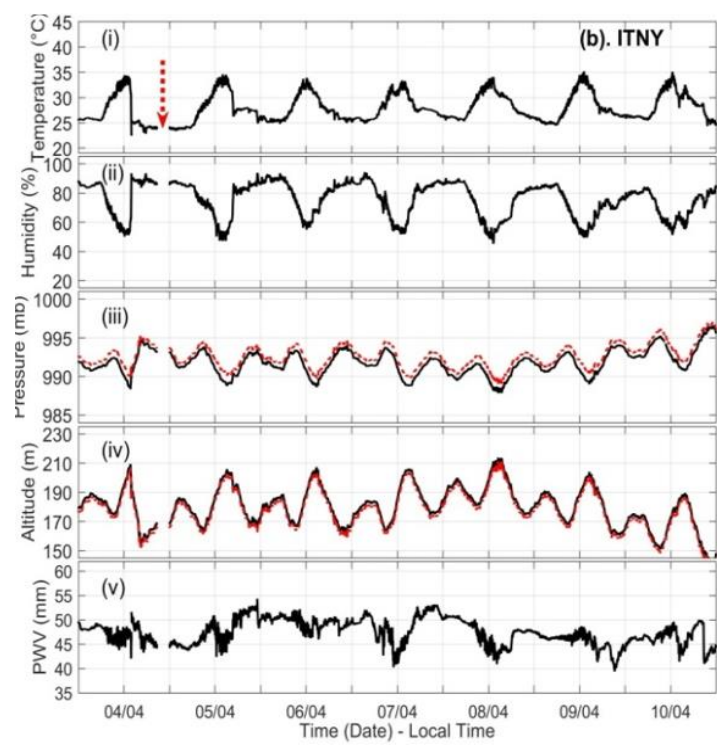

(b)

Figure 6. One-week observation and validation of meteorological parameters during outdoor measurement at; (a) GUWO, (b) ITNY sites

Table 3. Comparison of meteorological parameters for one week of measurement for the GUWO and ITNY sites as compared to estimation of reference value

\begin{tabular}{lllllllll}
\hline & \multicolumn{3}{c}{ GUWO } & & & ITNY \\
\multicolumn{1}{c}{ Parameter } & \multicolumn{1}{c}{ Range $^{*)}$} & Average & \multicolumn{1}{c}{ STD } & Error $(\%)$ & \multicolumn{1}{c}{ Range $^{*)}$} & Average & STD & Error $(\%)$ \\
\hline Temperature $\left({ }^{\circ} \mathrm{C}\right)$ & $24.17-46.32$ & 28.777 & 3.271 & $\left.2.359^{* *}\right)$ & $22.45-35.20$ & 27.97 & 2.738 & $\left.0.255^{* *}\right)$ \\
Humidity $(\%)$ & $24.86-88.63$ & 69.514 & 12.705 & $\left.-0.443^{* *}\right)$ & $45.17-94.26$ & 75.56 & 11.900 & $\left.5.89^{* *}\right)$ \\
Pressure $(\mathrm{mb})$ & $985.65-993.75$ & 989.357 & 1.483 & -0.099 & $987.83-996.59$ & 991.76 & 1.598 & -0.085 \\
Altitude $(\mathrm{m})$ & $163.61-232.41$ & 200.853 & 12.592 & 0.039 & $139.67-213.84$ & 180.42 & 13.541 & 0.038 \\
PWV $(\mathrm{mm})$ & $37.89-59.94$ & 45.990 & 2.657 & $* * *$ & $39.38-54.35$ & 47.43 & 2.564 & $* * *$ \\
\hline
\end{tabular}

*) Range is a value for min and max

**) The percentage error for temperature and relative humidity is from a daily basis (see Figure 7)

***) PWV is not measured directly from the sensor
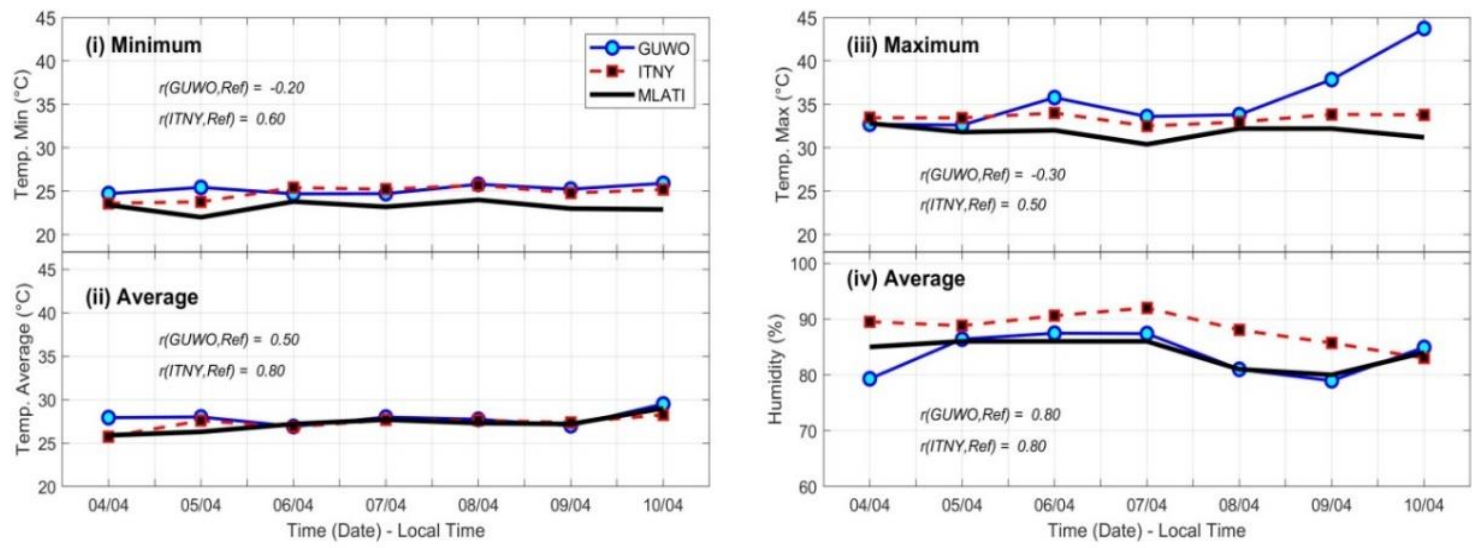

Figure 7. Validation of surface temperature on a daily basis for values, (i) minimum, (ii) average, (iii) maximum, and (iv) average of relative humidity

\section{CONCLUSION}

The first study in developing a low-cost weather system deployed for measuring precipitable water vapor (PWV) on a micro-scale and other meteorological parameters using the Arduino Uno and the BME280 sensor has been successful. The system was developed with several modules to enhance their performance such as DS3231 RTC, BME280 sensor, SD card, and $\mathrm{I}^{2} \mathrm{C}$ LCD. The advantages of the developed low-cost 
monitoring system are; 1 ) the capability to measure the surface meteorology, monitor, and store daily data automatically to a micro SD card as well as send to LCD or serial monitors; 2) capable to compute PWV directly; 3) accurate time during measurement and has self-recovery if the electricity shutdown; and 4) a portable system that can be carried and placed anywhere as long as an external battery is available. The indoor and outdoor experimental test carried out found that measured meteorological parameters showed positively correlated with estimation or reference values. The pattern of relative humidity is opposite to that of surface temperature. The air pressure with a bimodal pattern is also opposite to the altitude. Under quiet conditions, the PWV is observed below $50 \mathrm{~cm}$ and its pattern follows the relative humidity. At this condition, found a strong relationship between PWV and relative humidity $(r=69.19 \%)$ and PWV and temperature $(r=$ $-44.56 \%$ ), significantly at the $99 \%$ confidence level. The correlation between pressure and altitude measurements with estimated values was $72.39 \%$ and $99.04 \%$, respectively. In other words, when the surface temperature reaches above $37^{\circ} \mathrm{C}$ and the relative humidity is below $40 \%$, the PWV value will reach above 50 $\mathrm{mm}$, and the pattern will follow the variation in surface temperature. In conclusion, the system has successfully detected the character of PWV. To achieve a robust and affordable automatic weather station (AWS) or become a permanent station, future research will need to improve and add other modules, for example, gas sensors to monitor air quality, solar radiation, wind speed, rain sensors, and so on. For longterm measurements at certain locations, the system needs to be equipped with an external battery, power bank, or adapter with an output of $12 \mathrm{~V} / 3 \mathrm{~A}$. To advance data logging, the system must be able to connect to $\mathrm{WiFi}$ so that measurements can be monitored remotely and daily files can be downloaded automatically.

\section{ACKNOWLEDGEMENTS}

The authors would like to thank the Institut Teknologi Nasional Yogyakarta (ITNY) for the support of publication. The author highly appreciates the Meteorology, Climatology, and Geophysics Agency of Indonesia (BMKG) Sleman Regency for providing online the daily surface meteorological data used in this study.

\section{REFERENCES}

[1] C. B. Field, V. Barros, T. F. Stocker and Q. Dahe (Eds), "Managing the risks of extreme events and disasters to advance climate change adaptation: A Special Report of Working Groups I and II of the Intergovernmental Panel on Climate Change," Cambridge University Press, Cambridge, UK, and New York, NY, USA, p. 582, 2012.

[2] F. Huang and W. Ma, "Analysis of Long-Term Meteorological Observation for Weather and Climate Fundamental Data over the Northern Tibetan Plateau," Advances in Meteorology, 2016, doi: 10.1155/2016/4878353.

[3] V. Thomas, "Climate change and natural disasters: Transforming economies and policies for a sustainable future," Taylor \& Francis, Routledge, London, 2017.

[4] J. S. Amorim, M. R. Viola, R. Junqueira, V. A. de Oliveira, and C. R. de Mello, "Evaluation of satellite precipitation products for hydrological modeling in the Brazilian Cerrado Biome," Water, vol. 12, no. 9, p. 2571, 2020, doi: 10.3390/w12092571.

[5] N. Hofstra, M. Haylock, M. New, P. Jones and C. Frei, "Comparison of six methods for the interpolation of daily, European climate data," Journal of Geophysical Research, vol. 113, D21110, 2008, doi: 10.1029/2008JD010100.

[6] R. Steinacker, D. Mayer and A. Steiner, "Data quality control based on self-consistency," Monthly Weather Review, vol. 139, no. 12, pp. 3974-3991, December 2011, doi: 10.1175/MWR-D-10-05024.1.

[7] C. Xu, J. Wang and Q. Li, "A new method for temperature spatial interpolation based on sparse historical stations," Journal of Climate, vol. 31, no. 5, pp. 1757-1770, March 2018, doi: 10.1175/JCLI-D-17-0150.1.

[8] R. P. Allan, "The role of water vapour in earth's energy flows," Surveys in Geophysics, vol. 33, no. 3-4, pp. 557-564, 2012, doi: 10.1007/s10712-011-9157-8.

[9] R. Acharya, "Satellite link performance, in Satellite Signal Propagation, Impairments and Mitigation," Academic Press, pp. 279-300, 2017.

[10] W. Suparta and K. M. Alhasa, "Modeling of precipitable water vapor using an adaptive neuro-fuzzy inference system in the absence of the GPS network," Journal of Applied Meteorology and Climatology, vol. 55, no. 10, pp. 2283-2300, October 2016, doi: 10.1175/JAMC-D-15-0161.1.

[11] W. Suparta, "The development of raspi-met system with Raspberry Pi3 for meteorological monitoring in remote areas," IOP Conference Series: Earth and Environmental Science, vol. 540, no. 1, p. 012086, 2020.

[12] A. D'Ausilio, “Arduino: A low-cost multipurpose lab equipment," Behavior research methods, vol. 44, no. 2 , pp. 305-313, October 2012, doi: 10.3758/s13428-011-0163-z.

[13] M. El-Abd, "A review of embedded systems education in the arduino age: lessons learned and future directions," International Journal of Engineering Pedagogy, vol. 7, no. 2, 2017, doi: 10.3991/ijep.v7i2.6845.

[14] “Arduino," [Online]. Available: https://www.arduino.cc/en/guide/introduction (accessed April 20, 2021).

[15] G. Piñeres-Espitia, A. Cama-Pinto, D. De La R. Morrón, F. Estevez, and D. Cama-Pinto, "Design of a low cost weather station for detecting environmental changes," Revista Espacios, vol. 38, no. 59, pp. 1-13, 2017. 
[16] Y. NarasimhaRao, P. Surya Chandra, V. Revathi, and N. Suresh Kumar, "Providing enhanced security in IoT based smart weather system," Indonesian Journal of Electrical Engineering and Computer Science, vol. 18, no. 1, pp. 9-15, April 2020, doi: 10.11591/ijeecs.v18.i1.pp9-15.

[17] C. Morón, J. P. Diaz, D. Ferrández, and P. Saiz, "Design, development and implementation of a weather station prototype for renewable energy systems," Energies, vol. 11, no. 9, p. 2234, 2018, doi: 10.3390/en11092234.

[18] P. R. Nicolae, A. Banu, S. Mocanu, and D. Saru, "Low cost technologies for awareness and early warning in conditions of severe weather," The 14th International Scientific Conference eLearning and Software for Education Bucharest, Bucharest Romania, vol. 2, pp. 349-354, April 2018, doi: 10.12753/2066-026X-18-118.

[19] F. Bouquet and J. Bobroff, "Project-based physics labs using low-cost open-source hardware, "American Journal of Physics, vol. 85, no. 3, pp. 216-222, 2017, doi: 10.1119/1.4972043.

[20] L. Ada, T. DiCola, B. Bearnes, G. Needell, and D. Herrada, "Adafruit BME280 Humidity + Barometric Pressure + Temperature Sensor Breakout," [Online]. Available: https://learn.adafruit.com/adafruit-bme280-humiditybarometric-pressure-temperature-sensor-breakout (accessed May 13, 2021).

[21] W. A. Smith, "Arduino Uno hardware manual: a reference and user guide for the arduino uno hardware and firmware," Create Space Independent Publishing Platform, 2019.

[22] World Meteorological Organization (WMO)/CIMO/ET-Stand-1/Doc. 10 (20.XI.2012), [Online]. Available: https://www.wmo.int/pages/prog/www/IMOP/meetings/SI/ET-Stand-1/Doc-10_Pressure-red.pdf

[23] W. G. Jardine, "Determination of altitude, In: van de Plassche O. (eds), Sea-Level Research," Sea-Level Research. Springer, Dordrecht, pp. 569-590, 1986, doi: 10.1007/978-94-009-4215-8_21.

[24] H. Ye, E. J. Fetzer, S. Wong, A. Behrangi, D. Yang, and B. H. Lambrigtson, "Increasing atmospheric water vapor and higher daily precipitation intensity over northern Eurasia," Geophysical Research Letters, vol. 42, no. 21, pp. 9404-9410, 2015, doi: 10.1002/2015GL066104.

[25] United Nations Office for the Coordination of Humanitarian Affairs (OCHA), "Tropical Cyclone Seroja," April 2021. [Online]. Available: https://reliefweb.int/disaster/tc-2021-000033-idn (accessed Sep. 15, 2021).

[26] "Volcano Discovery," [Online]. Available: https://www.volcanodiscovery.com/earthquakes/6196956/2021-0410/07h00/magnitude6-Indonesia.html (accessed May 14, 2021).

[27] Pusat Database BMKG,"’ [Online]. Available: https://dataonline.bmkg.go.id/data_iklim (accessed May 14, 2021).

[28] K. Qin, L. X. Wu, A. De Santis, and G. Cianchini, "Preliminary analysis of surface temperature anomalies that preceded the two major Emilia 2012 earthquakes (Italy)," Annals of Geophysics, vol. 55, no. 4, 2012; doi: 10.4401/ag-6123.

\section{BIOGRAPHIES OF AUTHORS}

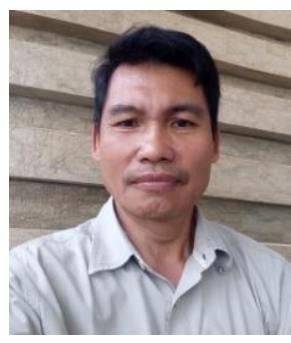

Wayan Suparta, has experience as a lecturer and researcher for over 25 years. His latest position is a principal lecturer at the Institut Teknologi Nasional Yogyakarta (ITNY). He began his career as a teacher of Physics, Electronics, and Computers in high school of SMUK Cor Jesu Malang (1994-1997) and SMUK Santo Aloysius Bandung (1997-2000), and a lecturer at the Electronics Engineering Department of Legenda College Group, Malaysia (2000-2004). He was appointed as a Post-Doctoral Fellow after his $\mathrm{PhD}(2007-2008)$ and subsequently appointed as a Senior Lecturer (1 July 2008 - 3 April 2012) and Associate Professor (4 April 2012 - 3 April 2017) at UKM. His teaching fields from undergraduate to postgraduate are communication electronics, analogue and digital systems, physics, robotics, machine learning, and advanced softcomputing, while his research is focused on GPS/GNSS technology, communication systems (remote sensing), smart systems, and artificial neural networks and data mining applications for sustainable environmental studies.

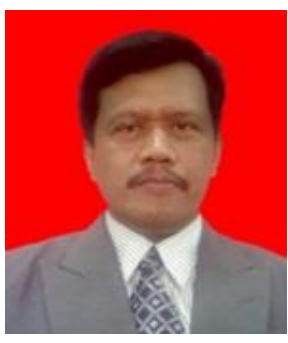

Aris Warsita, graduated as a Mechanical Engineer in 2007 from the Department of Mechanical Engineering, Institut Teknologi Nasional Yogyakarta. He got the magister degree in internal combustion engine in 2004 from the Gadjah Mada University, and earned a Ph.D. in 2016 from the Universiti Sains Malaysia. He is a lecturer at the Department of Mechanical Engineering of Institut Teknologi Nasional Yogyakarta and a member of the research Renewable Energy Research from Biomass with the topic "Tar Removal product gas reactor gasifier".

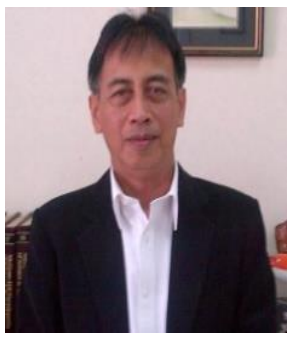

Ircham graduated as a Civil Engineer from Gadjah Mada University, Yogyakarta, Indonesia in 1985. He earned a Masters in Transportation Systems in 1997 and a Doctorate (Ph.D.) in 2018 from the same university from his undergraduate years. Since 1994, he is a lecturer at the Sekolah Tinggi Teknologi Nasional Yogyakarta (now became Institut Teknologi Nasional Yogyakarta). His research interest is on urban transportation, particularly rail-based transportation systems. 